\title{
The Role of the Solvent in Determining the Surface Texture of Magnesium Hydroxide
}

\author{
Charalambos A. Papatryfonos , Charis R. Theocharis* \\ Porous Solids Group, Department of Chemistry, University of Cyprus, Nicosia, Cyprus \\ charis@ucy.ac.cy
}

Abstract: The effect of the solvent on the surface properties of magnesium hydroxide was investigated in this study. The parameters examined were the effect of $\mathrm{OH}^{+} / \mathrm{Mg}^{2+}$ ratio, solvent composition and the ionic strength. The effect of the different variables was investigated by varying systematically some preparation conditions while keeping the others constant. The synthesized magnesium hydroxide samples physicochemical characteristics such as pore volume, specific surface area, pore size distribution, particle size and the amount of exchangeable $-\mathrm{OH}$ groups were found to be strongly influenced by the investigated preparation conditions. The powders were characterized by X Ray Diffraction (XRD), Thermogravimetric Analysis (TGA), Scanning Electron Microscopy (SEM) and Fourier Transform Infrared Spectroscopy FTIR.

\section{INTRODUCTION}

Solid magnesium oxide and hydroxide is used in various processes and finds many applications in a variety of fields such as water treatment [1-3], heat storage [4,5] $\mathrm{CO}_{2}$ storage [6,7] and sound absorption [8] among many others. As a result its surface chemical and textural properties have been extensively studied by several authors. For example, Pilarskaa et al have studied the effect of the use of non-ionic modifiers during precipitation on the physicochemical and functional properties of magnesium hydroxides [9]. Carrott et al studied the mechanism of the thermal decomposition of magnesium hydroxide to magnesium oxide by measuring water vapour adsorption isotherms on partially decomposed magnesium hydroxides samples [10]. Kumari et al have studied the optical and electrical properties of magnesium oxide micro- and nano-structures synthesized under various conditions [11]. The surface area, basicity and base strength distribution of magnesium oxide obtained from magnesium hydroxide prepared using various synthesis conditions and ageing periods, have been investigated. The surface properties were found to be strongly influenced by the preparation conditions for the precursor, magnesium hydroxide, and the calcination conditions used [12]. Clifford et al have used a liquid-liquid reaction to synthesize $\mathrm{Mg}(\mathrm{OH})_{2}$ using spinning disc reactor showing that the concentration ratio and reactant concentration and mixing conditions had a great affect on the particle size [13]. Superfine magnesium hydroxide with monodispersity was reported to be synthesized via direct precipitation method exhibiting a pure high crystalline material [14]. Among other applications, magnesium hydroxide is commonly used as flame-retardant filler in composite materials as it consumes energy during its thermal decomposition releasing water and forming an oxide layer, therefore its properties are studied extensively towards this use [15-21], as well as a precursor for magnesium oxide refractory ceramic [22]. The microstructure of the powder is of prime importance in both technical applications. The influence of synthesis parameters on the morphological characteristics of magnesium hydroxide nanoparticles precipitated in dilute aqueous medium was studied [23].

The precipitation of the hydroxide from alcoholic solutions to form transparent nanocomposite crystals with polymers was shown to have applications in optical applications [24]. Mesoporous magnesium oxide (Mg0) material was synthesized using an integration of the evaporation-induced surfactant assembly and magnesium nitrate pyrolysis which delivers a well crystalline high-surface area mesoporous product [25]. The performance 
The Role of the Solvent in Determining the Surface Texture of Magnesium Hydroxide

of $\mathrm{MgO}$ as a transesterification catalyst was studied through the modification of its surface basicity. Such modifications were carried out by different heat treatments, and the modification of surface characteristics by covering the surface by carbonate and hydroxyl groups [26].

Previous work in these laboratories has concentrated on the study of the surface chemical properties of calcium hydroxide and how synthesis conditions influence these [27-29]. As part of these studies, the application of a non-aqueous environment during synthesis has been studied, including how the surface chemistry of the product is influenced $[30,31]$. In the present paper, a study of the effect of synthesis conditions on the properties of magnesium hydroxide is presented, including the use of mixed solvent conditions, as well as the effect of altering reagent rations, as well as the ionic strength of the reaction liquor.

\section{EXPERIMENTAL}

Magnesium hydroxide was prepared by carefully mixing solutions of magnesium nitrate hexahydrate $\left(\mathrm{Mg}\left(\mathrm{NO}_{3}\right)_{2}\right.$ - $6 \mathrm{H}_{2} \mathrm{O}$ ) and sodium hydroxide. Reagents used were of reagent grade without further purification. Different reaction parameters were varied in order to examine their influence on the surface properties of magnesium hydroxide. The variables examined were $\mathrm{pH}$, precursor/precipitating agent ratio, and solvent composition. Magnesium hydroxide was precipitated by adding the sodium hydroxide solution to the magnesium salt solution with vigorous stirring, at $25^{\circ} \mathrm{C}$. A series of samples were prepared with different $\mathrm{OH}^{-} / \mathrm{Mg}^{2+}$ ratio by varying the reactants solution volume while the precursor and precipitating agent concentration was kept constant at $1 \mathrm{M}$ in both cases. The effect of varying precipitating agent concentration was also examined in a second series of samples by altering the $\mathrm{NaOH}$ concentration while maintaining the reactants volume stable. In both the series of samples the effect of the solvent on the surface properties was examined by performing the precipitation in water and ethanol/water solvent with ethanol water ratio of 1:1. The precipitates were left to stand in the mother liquor for $24 \mathrm{~h}$, filtered and washed several times with deionised water. Next, the samples were dried under vacuum at $40{ }^{\circ} \mathrm{C}$ for $24 \mathrm{~h}$ yielding a white $\mathrm{Mg}(\mathrm{OH})_{2}$ powder. All samples prepared are presented in Tables 1 and 2. A series of samples was also synthesized with the precipitates left to stand in the mother liquor for 5 minutes as summarized in Table 3 in order to examine the effect of ageing on the samples surface properties.

Nitrogen adsorption isotherm measurements were carried out at $77 \mathrm{~K}$ using an ASAP 2010 Micrometrics apparatus. The samples were degassed prior to the measurements at $373 \mathrm{~K}$ for $24 \mathrm{~h}$. The BET equation was used to calculate the surface areas whilst the pore size distributions were estimated using density functional theory (DFT) methods employing a slit shaped pore model. The thermal stability and behavior was studied by thermogravimetric analysis (TGA) using a Shimadzu apparatus. The measurements were carried out in air up to $873 \mathrm{~K}$ and the heating rate was $10 \mathrm{~K} \mathrm{~min}^{-1}$. The FTIR measurements were performed using a Shimadzu spectrometer (FTIR-8501). Powder X ray diffraction was used to determine the crystallinity and to estimate the particle size. Measurements were carried out on a Shimadzu 6000 diffractometer using Ko radiation $(\lambda=0,15478 \mathrm{~nm})$.

The Point of Zero Charge (PZC) was measured for a series of samples using a potentiometric titration method. $150 \mathrm{mg}$ of magnesium hydroxide were suspended in $100 \mathrm{ml}$ of a $\mathrm{NaCl} 0.1 \mathrm{M}$ solution, to which $10 \mathrm{ml}$ of a $0.2 \mathrm{M}$ sodium hydroxide solution was added. A blank sample was prepared with the same composition without the magnesium hydroxide. The final suspension was titrated potentiometrically, using a pH electrode, against a $0.1 \mathrm{M}$ hydrochloric acid solution, and compared to the titration for the blank. Where the two titration curves meet was the PZC value.

\section{RESUlts AND Discussion}

Effect of $\mathrm{OH}^{-} / \mathrm{Mg}^{2+}$ ratio and solvent composition 
The Role of the Solvent in Determining the Surface Texture of Magnesium Hydroxide

Table 1. Pore volume, SA and average pore diameter of magnesium hydroxide precipitated with varying $\mathrm{Na}+/ \mathrm{Mg} 2+$ by changing the solutions volume while the concentration of magnesium salt and sodium hydroxide was kept constant at $1 M$.

\begin{tabular}{|c|c|c|c|c|c|c|}
\hline & Solvent & $\begin{array}{l}\mathrm{Mg}\left(\mathrm{NO}_{3}\right)_{2} \cdot 6 \mathrm{H}_{2} \mathrm{O} \\
\left(\mathrm{cm}^{3}\right)\end{array}$ & $\begin{array}{l}\mathrm{NaOH} \\
\left(\mathrm{cm}^{3}\right)\end{array}$ & $\begin{array}{l}\text { Pore Volume } \\
\left(\mathrm{cm}^{3} / \mathrm{g}\right)\end{array}$ & $\begin{array}{l}S_{\text {BET }} \\
\left(\mathrm{m}^{2} / g\right)\end{array}$ & $\begin{array}{ll}\text { Pore } & \text { Diameter } \\
\text { (nm) } & \\
\text { (DFT) } & \end{array}$ \\
\hline 1 & $\mathrm{H}_{2} \mathrm{O}$ & 150 & 50 & 0.49 & 72 & 50 \\
\hline 2 & $\mathrm{H}_{2} \mathrm{O}$ & 100 & 50 & 0.52 & 74 & 37 \\
\hline 3 & $\mathrm{H}_{2} \mathrm{O}$ & 50 & 50 & 0.38 & 70 & 34 \\
\hline 4 & $\mathrm{H}_{2} \mathrm{O}$ & 50 & 100 & 0.41 & 88 & 22 \\
\hline 5 & $\mathrm{H}_{2} \mathrm{O}$ & 50 & 150 & 0.42 & 113 & 16 \\
\hline 6 & $\mathrm{H}_{2} \mathrm{O} / \mathrm{EtOH}$ & 150 & 50 & 0.41 & 78 & 30 \\
\hline 7 & $\mathrm{H}_{2} \mathrm{O} / \mathrm{EtOH}$ & 100 & 50 & 0.34 & 49 & 34 \\
\hline 8 & $\mathrm{H}_{2} \mathrm{O} / \mathrm{EtOH}$ & 50 & 50 & 0.19 & 29 & 34 \\
\hline 9 & $\mathrm{H}_{2} \mathrm{O} / \mathrm{EtOH}$ & 50 & 100 & 0.41 & 88 & 22 \\
\hline 10 & $\mathrm{H}_{2} \mathrm{O} / \mathrm{EtOH}$ & 50 & 150 & 0.32 & 128 & 10 \\
\hline
\end{tabular}

As it can be seen from Table $1, \mathrm{OH}^{-} / \mathrm{Mg}^{2+}$ ratio has a strong influence on some surface properties of the product. Specifically, where water was used as the solvent for $\mathrm{NaOH}$, there was an increase in the pore width with a decrease in $\mathrm{OH}^{-} / \mathrm{Mg}^{2+}$ ratio. Where the solvent was a $\mathrm{H}_{2} \mathrm{O} / \mathrm{EtOH} \mathrm{1:1} \mathrm{mixture,} \mathrm{both} \mathrm{specific} \mathrm{surface} \mathrm{area} \mathrm{and}$ average pore diameter was lower than for the corresponding $\mathrm{OH} / \mathrm{Mg}^{2+}$ ratios where the solvent was water only.

Differences could be attributed to the difference in the solubility of magnesium hydroxide between water and ethanol thus affecting precipitation speed and thus the cystal shape and size. Further, ethanol molecules could be affecting the crystallization process by solvent - crystal surface interactions. However, precipitation times were measured for a series of syntheses both in the presence of ethanol and without, and in all cases solid material appeared within $2 \mathrm{~s}$ of mixing the reagents together, thus it is suggested that differences in the surface properties were attributable to crystallite shape and size changes.

The contents of Table 2 show the effect of the $\mathrm{OH}^{-} / \mathrm{Mg}^{2+}$ ratio while varying the sodium hydroxide concentration and keeping the same solution volume in both water and ethanol/water mixtures used as solvents. From Table 2 , it can be seen that at higher $\mathrm{OH}^{-} / \mathrm{Mg}^{2+}$ ratio, the surface area increased significantly while the pore volume remained approximately the same. This may be due to the particle size of the product being dependent on the $\mathrm{OH}^{-} / \mathrm{Mg}^{2+}$ ratio. Additionally, altering the $\mathrm{OH}^{-} / \mathrm{Mg}^{2+}$ ratio strongly affects the rate at which the magnesium hydroxide precipitates and thus influences the surface properties.

Table 2. Pore volume, SA and average pore diameter of magnesium hydroxide precipitated with varying $\mathrm{NaOH}$ concentration $\mathrm{OH}-/ \mathrm{Mg} 2+$. The magnesium salt and precipitating agent solution volume was kept constant.

\begin{tabular}{|l|l|l|l|l|l|l|l|}
\hline & Solvent & $\begin{array}{l}\mathbf{M g}\left(\mathbf{N O}_{3}\right)_{2} \mathbf{6 H}_{2} \mathbf{O} \\
\left(\mathbf{c m}^{3}\right)\end{array}$ & $\begin{array}{l}\mathbf{N a O H} \\
\left(\mathbf{c m}^{3}\right)\end{array}$ & $\begin{array}{l}\mathbf{N a O H} \\
\mathbf{M o l} / \mathbf{L}\end{array}$ & $\begin{array}{l}\text { Pore } \\
\text { Volume } \\
\left(\mathbf{c m}^{3} / \mathbf{g}\right)\end{array}$ & $\begin{array}{l}\mathbf{S}_{\mathrm{BET}} \\
\left(\mathbf{m}^{2} / \mathbf{g}\right)\end{array}$ & $\begin{array}{l}\text { Pore Diameter } \\
(\mathbf{n m}) \text { (DFT) }\end{array}$ \\
\hline $\mathbf{1}$ & $\mathrm{H}_{2} \mathrm{O}$ & 50 & 50 & 1 & 0.38 & 70 & 34 \\
\hline $\mathbf{2}$ & $\mathrm{H}_{2} \mathrm{O}$ & 50 & 50 & 2 & 0.45 & 120 & 22 \\
\hline
\end{tabular}


The Role of the Solvent in Determining the Surface Texture of Magnesium Hydroxide

\begin{tabular}{|c|c|c|c|c|c|c|c|}
\hline$\overline{4}$ & $\begin{array}{l}\mathrm{H}_{2}^{2} \mathrm{O} / \\
\mathrm{EtOH}^{2}\end{array}$ & 50 & 50 & 1 & 0.19 & 29 & 35 \\
\hline 5 & $\begin{array}{l}\mathrm{H}_{2} \mathrm{O} / \\
\mathrm{EtOH}^{2}\end{array}$ & 50 & 50 & 2 & 0.53 & 109 & 31 \\
\hline 6 & $\begin{array}{l}\mathrm{H}_{2} \mathrm{O} / \\
\mathrm{EtOH}^{2}\end{array}$ & 50 & 50 & 3 & 0.40 & 107 & 17 \\
\hline
\end{tabular}

\section{EFFECT OF IONIC STRENGTH}

In order to examine if the surface properties also depend upon the ionic strength, magnesium hydroxide samples precipitated by varying the $\mathrm{NaOH}$ concentration were compared to samples precipitated using the same $\mathrm{NaOH}$ concentration in each synthesis and varying the volume used. This was done in order to compare samples prepared from reaction mixtures having the same $\mathrm{OH}^{-} / \mathrm{Mg}^{2+}$ ratio but different ionic strength. In all cases, samples were precipitated using the same $\mathrm{OH}^{-} / \mathrm{Mg}^{2+}$ ratio and water was used as the $\mathrm{NaOH}$ solvent. From the data in Table 2 it can be seen that the average pore diameter was reduced with increasing $\mathrm{OH}^{-} / \mathrm{Mg}^{2+} \mathrm{ratio}$. This reduction was more pronounced when the ionic strength increases as seen for $\mathrm{OH}^{-} / \mathrm{Mg}^{2+}$ ratio values of 2 and 3. The effect of the ionic strength can also be related with the increase of the specific surface area with increasing ionic strength for $\mathrm{OH}^{-} / \mathrm{Mg}^{2+}$ ratio values of 2 and 3. The thermogravimetric data (TGA) for $\mathrm{Mg}(\mathrm{OH})_{2}$ samples with $\mathrm{NaOH}$ concentration of 1-3 $\mathrm{M}$ is displayed in Figure 1 . The weight loss at $320^{\circ} \mathrm{C}$ corresponds to the loss of crystallization water and the decomposition of magnesium hydroxide to form crystalline $\mathrm{MgO}$ through a reorganization of its structure. It is obvious that with increasing precipitating agent concentration this weight loss step is being reduced indicating that the tightly bound water is less with increasing $\mathrm{NaOH}$ concentration. This effect is stronger where $3 \mathrm{M} \mathrm{NaOH}$ was used. This is also confirmed from the corresponding FTIR spectra shown in Figure 2 where the peak at $3695 \mathrm{~cm}^{-1}$ which corresponds to the asymmetric stretch of hydroxyl (-OH) groups of $\mathrm{Mg}(\mathrm{OH})_{2}$ is being clearly reduced with the $\mathrm{NaOH}$ concentration being increased to $3 \mathrm{M}$. The broad band at $3444 \mathrm{~cm}^{-1}$ was assigned to $\mathrm{OH}_{\ldots} . . \mathrm{OH}_{2}$ and $\mathrm{H}_{2} \mathrm{O} \ldots \mathrm{OH}_{2}$ vibrations. The peak at $1650 \mathrm{~cm}^{-1}$ corresponds to the $-\mathrm{OH}$ stretching vibrations of water molecules and $1390 \mathrm{~cm}^{-1}$ is attributed to the bending vibration of the $\mathrm{Mg}-\mathrm{OH}$ and $-\mathrm{OH}$ bond in crystal structure.

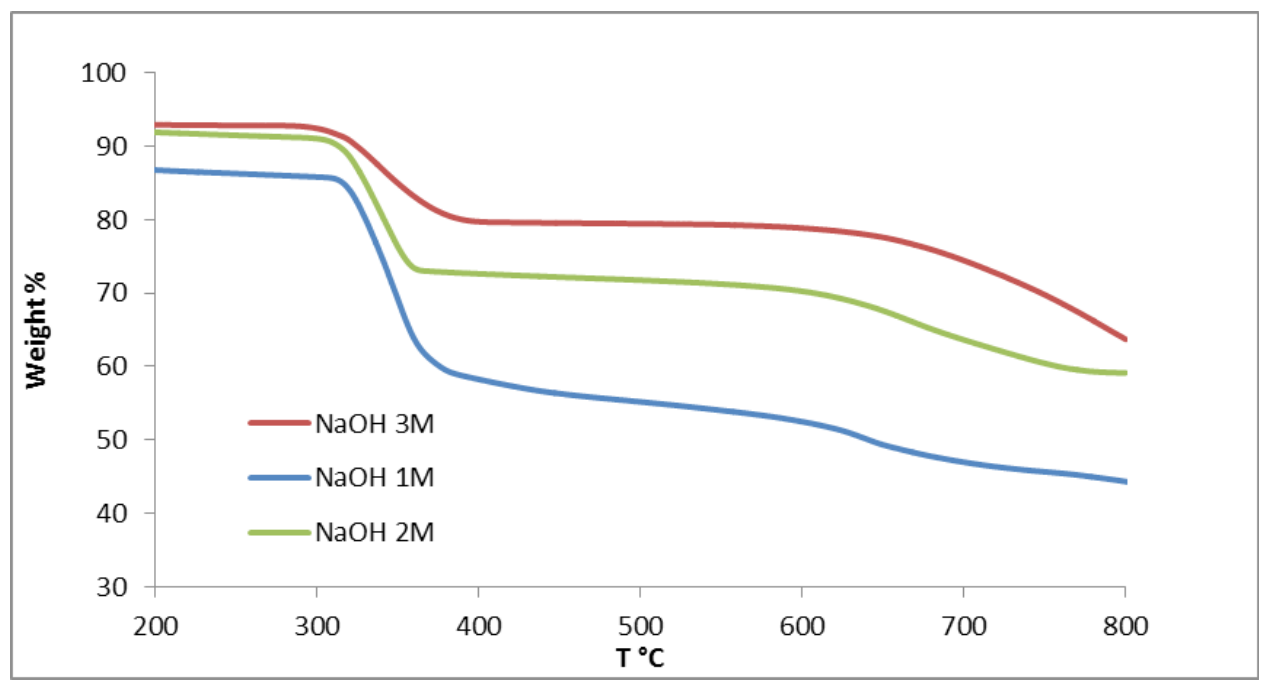

Fig1. Thermogravimetric analysis of magnesium hydroxide samples precipitated using NaOH 1M (blue), 2M

(green) and $3 M($ red). 


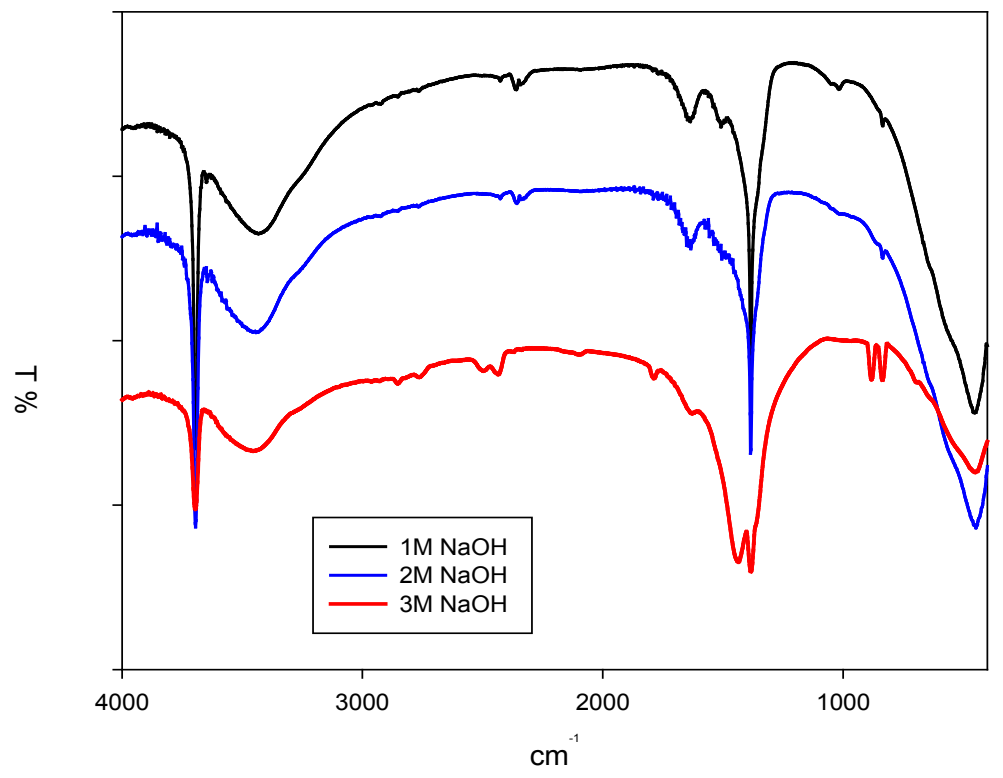

Fig 2. Ft-IR spectra of magnesium hydroxide samples precipitated using NaOH 1M, 2M 3M.

In addition to the FTIR measurements, the presence of surface - $\mathrm{OH}$ functional groups was shown by deuterium oxide exchange, as shown in Figure 3. From these spectra, it can be seen that the peak appearing at $2715 \mathrm{~cm}^{-1}$ indicates the amount of the accessible functional $-\mathrm{OH}$ groups where there has been a deuterium exchange. It is shown that the number of exchangeable - $\mathrm{OH}$ groups is higher with increasing $\mathrm{NaOH}$ concentration as it has higher deuterium exchange when exposed to heavy water vapor. Therefore, it can be stated that the samples prepared using higher $\mathrm{NaOH}$ concentration, proportionally, have a larger number of accessible - $\mathrm{OH}$ structural groups. This can also be justified by the smaller particle size of this sample calculated using the Debye-Scherrer equation using X-ray diffraction as shown in Figure 4.

$\mathrm{Mg}$ exposed to heavy water vapour

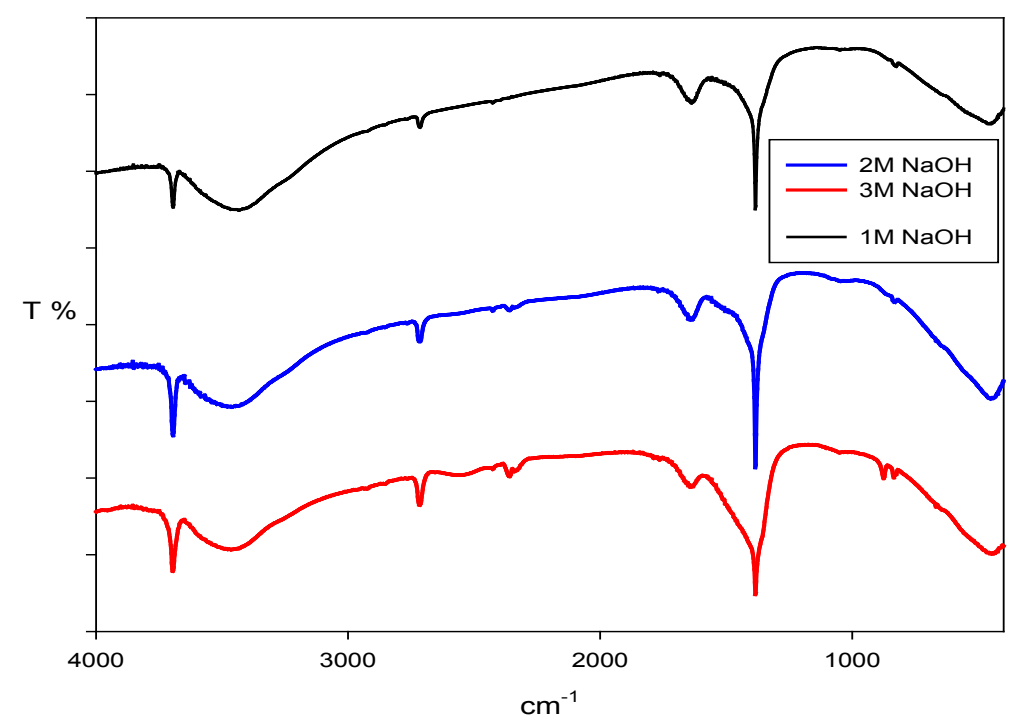

Fig 3. FTIR spectra of magnesium hydroxide samples precipitated using NaOH 1M, 2M and 3M exposed to heavy water vapour (deuterium oxide). 


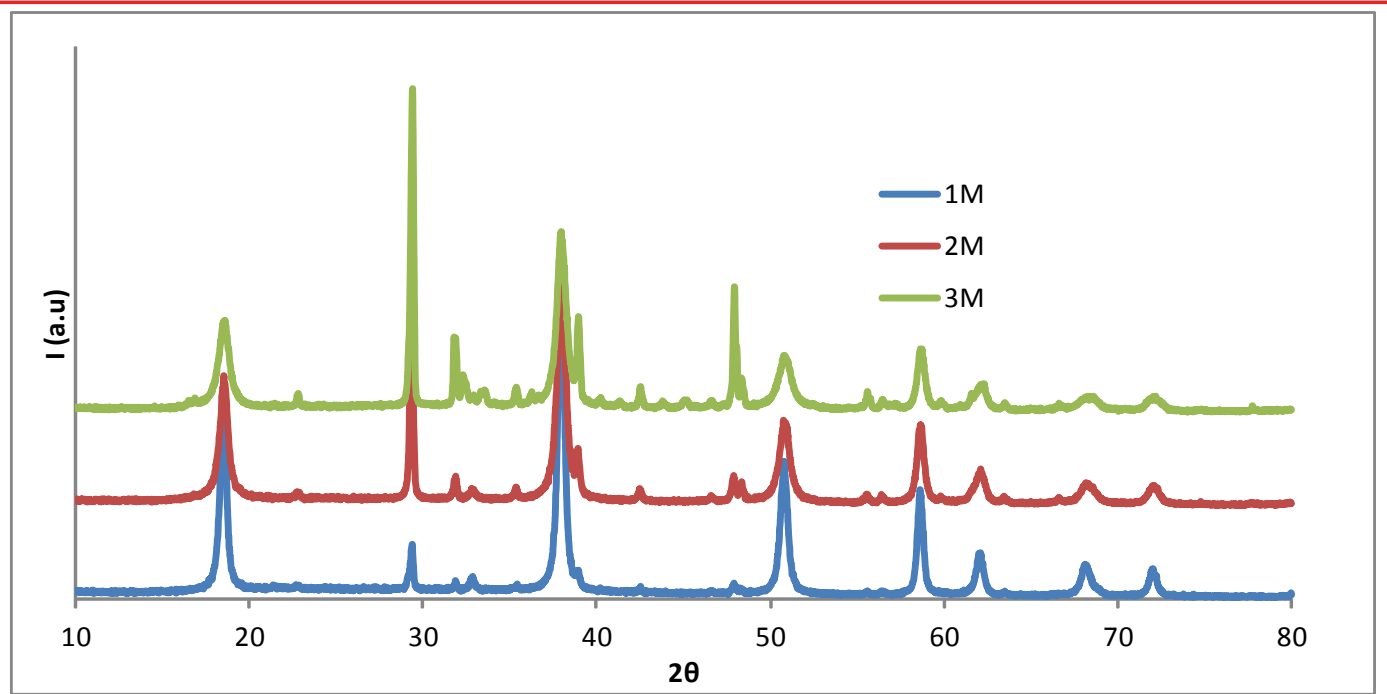

Fig 4. XRD patterns of magnesium hydroxide precipitated using sodium hydroxide $1 M, 2 M$ and $3 M$

The X-Ray Diffraction patterns of the synthesized materials using $\mathrm{NaOH} 1-3 \mathrm{M}$ as precipitating agent are illustrated in Figure 4. The particle size calculated with the use of the Debye-Scherrer equation was $19 \mathrm{~nm}$ for $1 \mathrm{M}$ $\mathrm{NaOH}, 15 \mathrm{~nm}$ for $2 \mathrm{M}$ and $12 \mathrm{~nm}$ for $3 \mathrm{M}$. As expected, the magnesium hydroxide particle size was being reduced with increasing precipitating agent concentration. Figures 5 to 7 show SEM micrographs for samples prepared from $\mathrm{EtOH} / \mathrm{H}_{2} \mathrm{O}$ solutions, for $\mathrm{OH}^{-} / \mathrm{Mg}^{2+}$ ratios from 1:1 to 1:3, indicating that the crystallite size increases with increasing ion ratios, without, however, a change in particle shape. Samples used here were uncalcined. Peaks at $2 \theta$ values of $29.5^{\circ} \mathrm{\kappa} \alpha \mathrm{l} 48^{\circ}$ seen where higher concentrations of $\mathrm{NaOH}$ were used, were not attributable to magnesium hydroxide and were presumably due to the presence of a mixed $\mathrm{MgO} / \mathrm{Mg}(\mathrm{OH})_{2}$ phase. The presence of this phase may well be partially the cause of some of the changes seen in surface properties. This phase is the source of the extra peaks observed at $800 \mathrm{~cm}^{-1}$ in the FTIR spectrum for the same sample.

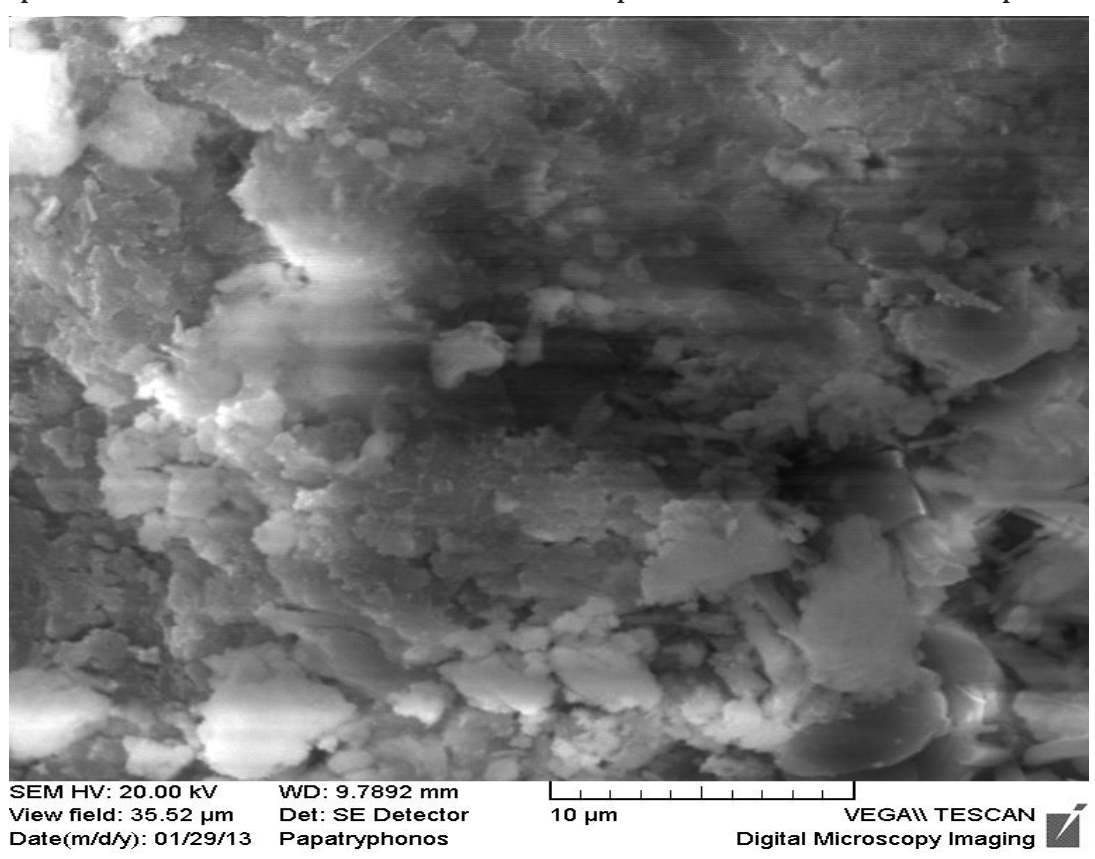

Fig 5. SEM Micrograph of $\mathrm{Mg}(\mathrm{OH}) 2$ prepared with 1:1 $\mathrm{OH}-/ \mathrm{Mg} 2+$ ratio. 


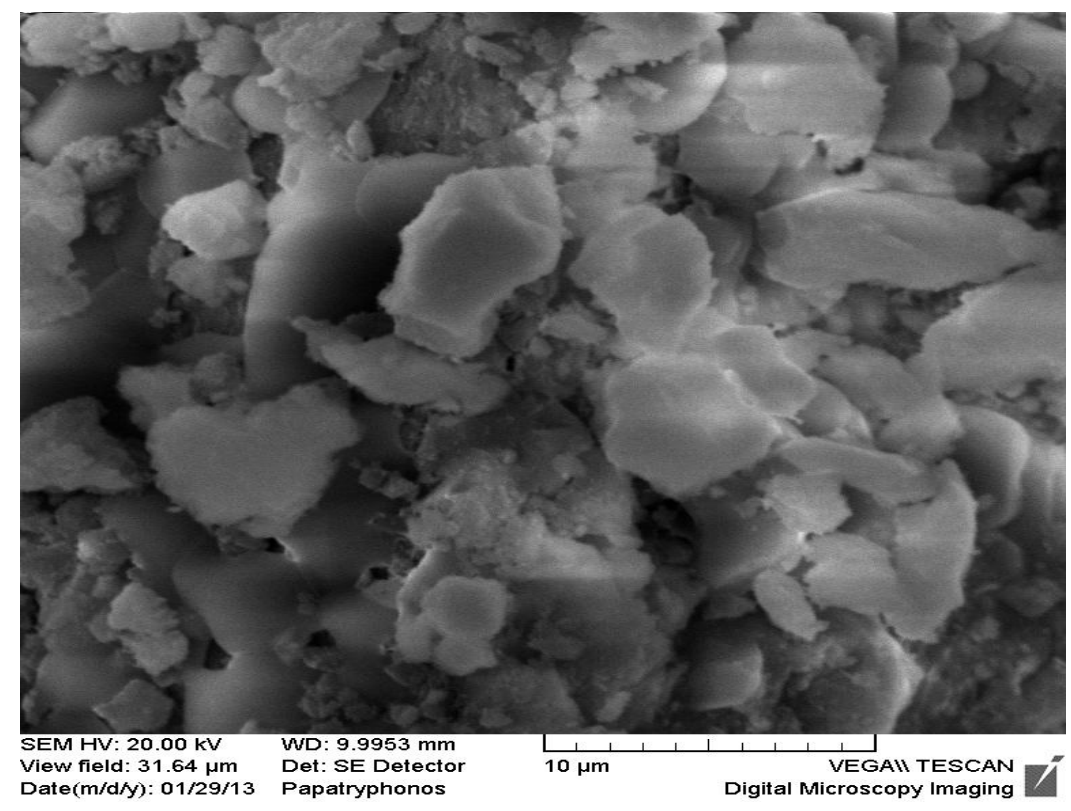

Fig 6. SEM Micrograph of $\mathrm{Mg}(\mathrm{OH}) 2$ prepared with 2:1 $\mathrm{OH}-/ \mathrm{Mg} 2+$ ratio.

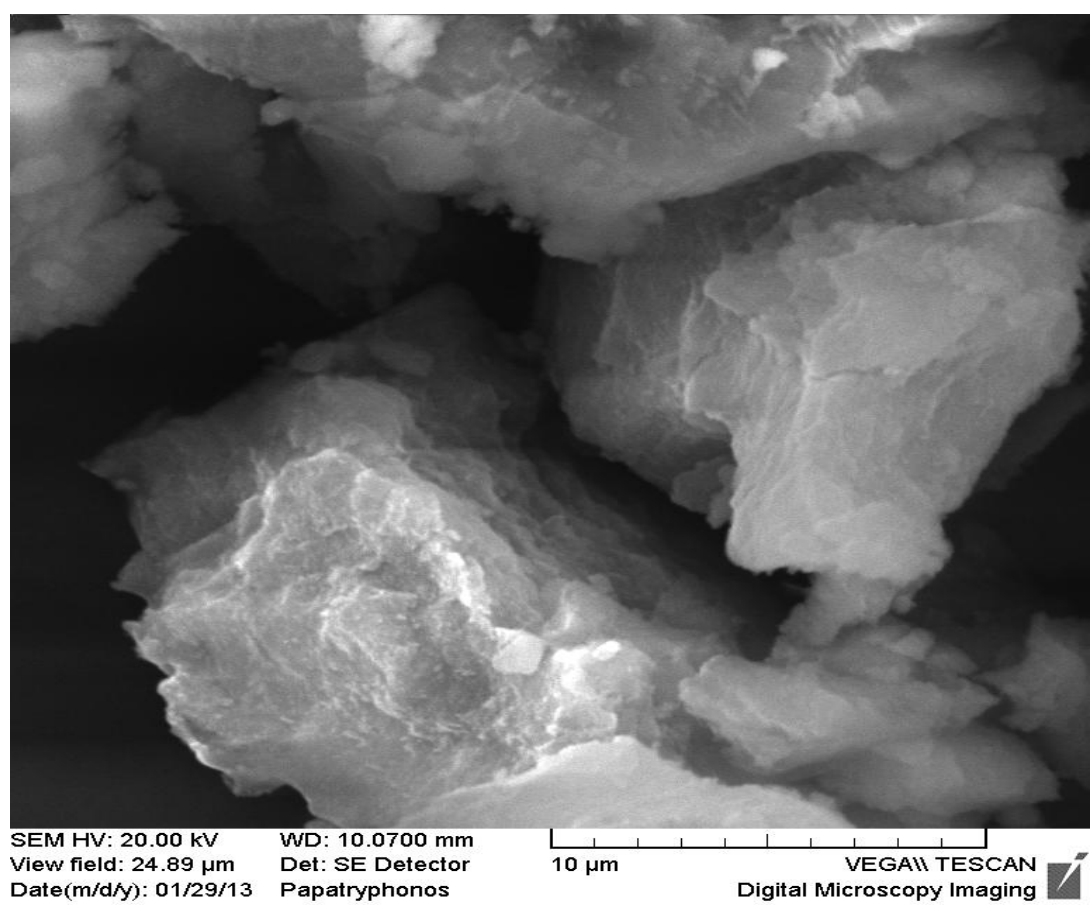

Fig 7. SEM Micrograph of Mg(OH)2 prepared with 3:1 $\mathrm{OH}-/ \mathrm{Mg} 2+$ ratio.

Figure 8 shows a characteristic titration curve for the sample of magnesium hydroxide precipitated with $1 \mathrm{M}$ $\mathrm{NaOH}$ solution in water. It can be seen from the intersection of the titration curves of the sample and the blank curve that PZC is at $\mathrm{pH}$ 10.40. Similar experiments for all other samples showed that for all samples the PZC was in the range of 10.40-10.85, well within the accepted error range for this technique. 
The Role of the Solvent in Determining the Surface Texture of Magnesium Hydroxide

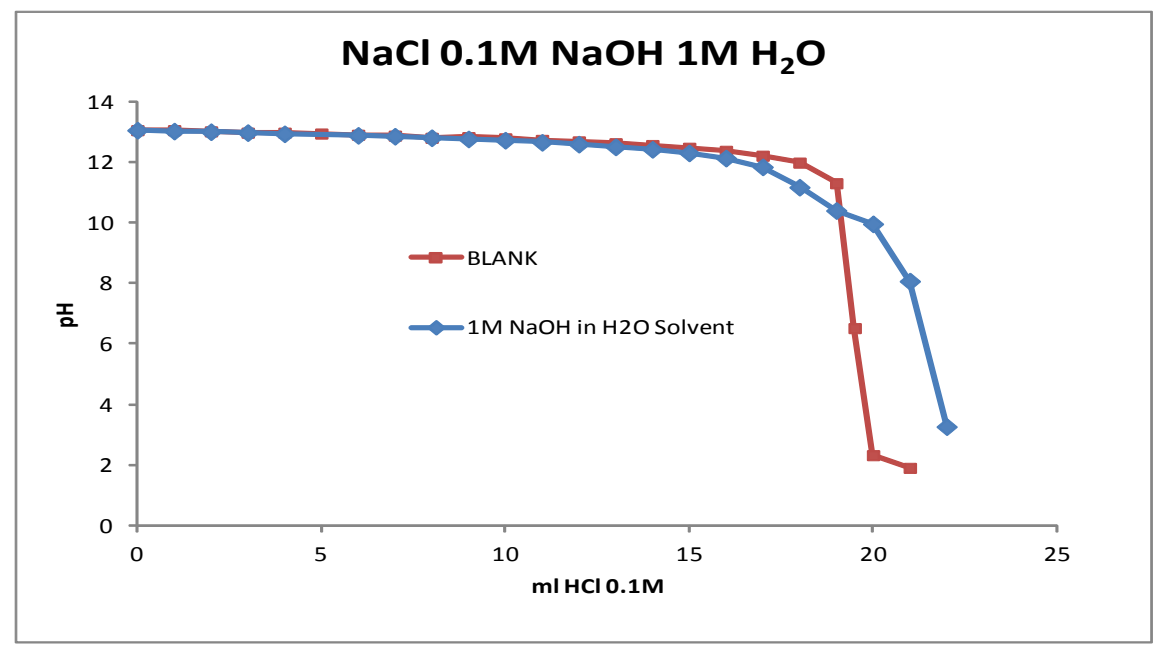

Fig 8. Potentiometric titration curve for magnesium hydroxide precipitated with $1 \mathrm{M} \mathrm{NaOH}$ in water solvent showing the PZC at pH 10.40.

\section{EFFECT OF AgEING}

The effect of ageing on the surface properties was examined with a series of samples that were left to stand in the mother liquor for 5 minutes. The results are shown in Table 3, and were compared with samples that were left to stand in their mother liquor for $24 \mathrm{~h}$ previously shown in Table 1.It can be seen that ageing has a pronounced effect on the pore properties of the resulting magnesium hydroxide. A shorter ageing period led to larger average pore diameter and lower surface areas than samples aged for $24 \mathrm{~h}$. This effect, presumably, is due to crystallization and further nucleation processes taking place to a different degree during ageing, and have a significant effect upon surface properties. However, ageing appears to have an irregular effect on the surface area.

Table 3. Pore volume, SA and average pore diameter of magnesium hydroxide precipitated with varying $\mathrm{Na+}$ / $\mathrm{Mg} 2+$ by changing the solutions volume while the concentration of magnesium salt and sodium hydroxide was kept constant at 1M. The precipitates were left to stand in mother liquor for $5 \mathrm{~min}$.

\begin{tabular}{|l|l|l|l|l|l|l|}
\hline & Solvent & $\begin{array}{l}\mathbf{M g}\left(\mathbf{N O}_{3} \mathbf{~}_{2} \cdot \mathbf{6 H}_{2} \mathbf{O}\right. \\
\left(\mathbf{c m}^{3} \mathbf{~}\right.\end{array}$ & $\begin{array}{l}\mathbf{N a O H} \\
\left(\mathbf{c m}^{3} \mathbf{~}\right.\end{array}$ & $\begin{array}{l}\text { Pore Volume } \\
\left(\mathbf{c m}^{\mathbf{3}} / \mathbf{g}\right)\end{array}$ & $\begin{array}{l}\mathbf{S}_{\text {BET }} \\
\left(\mathbf{m}^{2} / \mathbf{g}\right)\end{array}$ & $\begin{array}{l}\text { Pore Diameter (nm) } \\
(\mathbf{D F T})\end{array}$ \\
\hline $\mathbf{1}$ & $\mathrm{H}_{2} \mathrm{O}$ & 50 & 50 & 0.33 & 51 & 35 \\
\hline $\mathbf{2}$ & $\mathrm{H}_{2} \mathrm{O}$ & 50 & 100 & 0.36 & 68 & 28 \\
\hline $\mathbf{3}$ & $\mathrm{H}_{2} \mathrm{O}$ & 50 & 150 & 0.30 & 77 & 18 \\
\hline $\mathbf{4}$ & $\mathrm{H}_{2} \mathrm{O} / \mathrm{EtOH}$ & 50 & 50 & 0.32 & 50 & 35 \\
\hline $\mathbf{5}$ & $\mathrm{H}_{2} \mathrm{O} / \mathrm{EtOH}$ & 50 & 100 & 0.24 & 67 & 19 \\
\hline $\mathbf{6}$ & $\mathrm{H}_{2} \mathrm{O} / \mathrm{EtOH}$ & 50 & 150 & 0.14 & 51 & 13 \\
\hline
\end{tabular}

\section{CONCLUSIONS}

The synthesized magnesium hydroxide pore volume, average pore width and specific surface area are strongly affected by the precipitation and crystallization conditions. They depend strongly upon the precipitating agent/ magnesium salt ratio, the $\mathrm{pH}$, ionic strength and the ageing regime used. Changing the preparation conditions 
The Role of the Solvent in Determining the Surface Texture of Magnesium Hydroxide

led to a change in surface texture, which is linked to a change in particle size, but not particle shape as indicated by the SEM micrographs shown above. It is intended to further analyse the data presented herein together with previous data obtained on calcium analogues by statistical methods used previously by us to extract more information from porous solids and other systems [32-35].

We thank the University of Cyprus for financial support of this research, and Ms Andrie Andreou for experimental assistance.

\section{REFERENCES}

1. L. Wei, J. Zhao, C. Xu, M. Liu, J. Taiwan Inst. Chem. Eng. 45 (2014) 2605-2609.

2. K. Wang, J. Zhao, H. Li, X. Zhang, H. Shi, J. Taiwan Inst. Chem. Eng. 61 (2016) 287291.

3. H. Li, S. Liu, J. Zhao, N. Feng, Colloids Surfaces A Physicochem. Eng. Asp. 494 (2016) 222-227.

4. M. Zamengo, J. Ryu, Y. Kato, Energy Procedia 71 (2015) 293-305.

5. A. Shkatulov, Y. Aristov, Energy 85 (2015) 667-676.

6. G. Dávila, J. Cama, S. Galí, L. Luquot, J.M. Soler, Int. J. Greenh. Gas Control 48 (2015) 171-185.

7. Q. Zhao, C. Liu, M. Jiang, H. Saxén, R. Zevenhoven, Miner. Eng. 79 (2015) 116-124.

8. G. Sung, J.W. Kim, J.H. Kim, J. Ind. Eng. Chem. 44 (2016) 99-104.

9. A. Pilarskaa, M. Wysokowskia, E. Markiewiczb, T. Jesionowskia, Powder Technol 235, (2013) 148-157.

10. M Carrott, PJM Carrott, Stud Surf Sci And Catal. 87 (1994) 497-506.

11. L. Kumari, WZ Li, C.H. Vannoy, RM Leblanc, DZ Wang, Ceram. Int. 35 (2009) 3355-336.

12. V. R. Choudhary and M. Y. Pandit, Appl. Catal. 71 (1991) 265-274.

13. Y Clifford. Tai, C. Tai, M. Chang, H. Liu, (2007) 5536-5541.

14. X.F. Wu, G.S. Hu, B.B. Wang, Y.F. Yang, J. Cryst. Growth 310 (2008) 457-461.

15. S. Elbasuney, S.F. Mostafa, Powder Technol. 278 (2015) 72-83.

16. H. Ma, Z. Chen, Z. Mao, Vacuum 95 (2013) 1-5.

17. H. Tang, X. Zhou, X. Liu, Procedia Eng. 52 (2013) 336-341.

18. S.P. Liu, J. Ind. Eng. Chem. 20 (2013) 2401-2408.

19. Y. Yang, M. Niu, J. Li, B. Xue, J. Dai, Polym. Degrad. Stab. 134 (2016) 1-9.

20. X. Li, T. Shi, P. Chang, H. Hu, J. Xie, Y. Liu, Powder Technol. 260 (2014) 98-104.

21. S. Lan, L. Li, D. Xu, D. Zhu, Z. Liu, F. Nie, Appl. Surf. Sci. 382 (2016) 56-62.

22. L.-Z. Pei, W.-Y. Yin, J.-F. Wang, J. Chen, C.-G. Fan, Q.-F. Zhang, Mater. Res. 13 (2010) 339-343.

23. C. Henrist, J.-P. Mathieu, C. Vogels, A. Rulmont, R. Cloots J. of Cryst. Growth 249 (2003) 321-330.

24. J-X. Wang, Q. Sun, B Chen, X. Wu, X Zeng, C Zhang, H-K Zou and J-F Chen Nanotechnology 26 (2015).

25. H Yonggan), X Shao, ,T Liu,B Li, S. Nie, Thermochim. Acta. 604 (2015) 45-51.

26. D. Cornu, H Guesmi, Laugel, G Laugel, JM Krafft, Lauron-Pernot, H Lauron-Pernot, Phys. Chem. Chem. Phys. 17 (2015) 14168-14176. 
The Role of the Solvent in Determining the Surface Texture of Magnesium Hydroxide

27. C.R. Theocharis, Mol. Cryst. Liq. Cryst., 187, (1990) 345-350.

28. C.R. Theocharis and D. Yeates, Colloids Surf. 58 (1991) 353-361.

29. J.O. Okonkwo, B.A. Colenutt, and C.R. Theocharis, in (Ed. H.A. Mottola and J.R. Steinmetz) Chem. Mod. Surf. (1992) 119-129.

30. I. Pashalidis and C.R. Theocharis, J. Chem. Technol. Biotechnol. 71 (1998) 223-226.

31. C.R. Theocharis, I. Pashalidis, S.L. Jordan, A.C. Gray, and D. Yeates, Mol. Cryst. Liq. Cryst. 356 (2001) 205214.

32. D. Ballabio, R. Kokkinofta, R. Todeschini, CR. Theocharis, Chemom. Intel. Lab. Syst. 87 (2007) 52-58.

33. R. I. Kokkinofta and C. R. Theocharis, J. Agric. Food Chem., 53 (2005) 5067-5073.

34. D. Ballabio, R. Kokkinofta, R. Todeschini, and C. R. Theocharis, Chemom. Intel. Lab. Syst. 87 (2007) 78-84.

35. Can C. Attipa, R. Kokkinofta and C. R. Theocharis, “Characterization of Porous Solids VIII”, (2009) 64-70.

Citation: Charalambos A. Papatryfonos, Charis R. Theocharis*, "The Role of the Solvent in Determining the Surface Texture of Magnesium Hydroxide". American Research Journal of Chemistry, 1(1); pp:1-10.

Copyright (C) Charalambos A. Papatryfonos , Charis R. Theocharis*, This is an open access article distributed under the Creative Commons Attribution License, which permits unrestricted use, distribution, and reproduction in any medium, provided the original work is properly cited. 